\title{
Pain after whiplash: a prospective controlled inception cohort study
}

\author{
Diana Obelieniene, Harald Schrader, Gunnar Bovim, Irena Miseviciene, Trond Sand
}

\begin{abstract}
Objectives-In Lithuania, there is little awareness of the notion that chronic symptoms may result from rear end collisions via the so-called whiplash injury. After most such collisions no contact with the health service is established. An opportunity therefore exists to study posttraumatic pain without the confounding factors present in western societies.

Methods-In a prospective, controlled inception cohort study, 210 victims of a rear end collision were consecutively identified from the daily records of the Kaunas traffic police. Neck pain and headache were evaluated by mailed questionnaires shortly after the accident, after 2 months, and after 1 year. As controls, 210 sex and age matched subjects were randomly taken from the population register of the same geographical area and evaluated for the same symptoms immediately after their identification and after 1 year.

Results-Initial pain was reported by $47 \%$ of accident victims; $10 \%$ had neck pain alone, $18 \%$ had neck pain together with headache, and $19 \%$ had headache alone. The median duration of the initial neck pain was 3 days and maximal duration 17 days. The median duration of headache was 4.5 hours and the maximum duration was 20 days. After 1 year, there were no significant differences between the accident victims and the control group concerning frequency and intensity of these symptoms. Conclusions-In a country were there is no preconceived notion of chronic pain arising from rear end collisions, and thus no fear of long term disability, and usually no involvement of the therapeutic community, insurance companies, or litigation, symptoms after an acute whiplash injury are self limiting, brief, and do not seem to evolve to the so-called late whiplash syndrome.

(f Neurol Neurosurg Psychiatry 1999;66:279-283)
\end{abstract}

Keywords: whiplash injury; neck pain; headache

It is generally agreed that rear end collisions may cause acute neck pain and headache, ${ }^{1}$ but there is sparse information about the proportion of an unselected cohort at risk that develops these symptoms. Despite numerous investigations, the prevalence and even the concept of chronic pain as a result of accident related physical injury (late whiplash syndrome) is still debated.

Lithuania is a country in which there is no or little awareness or experience among the general population of the notion that a whiplash injury may cause chronic pain and disability. Accident victims with acute symptoms from rear end collisions generally view this as a benign injury not requiring any medical attention. In a controlled historical cohort study ${ }^{3}$ none of the 202 subjects involved in a car collision with rear end impact 1-3 years earlier had persistent or disabling complaints that could be conceivably linked to the accident. No significant differences between the accident victims and controls concerning prevalence of symptoms including neck pain, headache, and subjective cognitive dysfunction at the time of the interview were found. Thus we hypothesised that cultural and psychosocial factors may be important in explaining why accident victims in some other societies report chronic symptoms. Such factors may include expectation of disability, symptom amplification as a result of such expectation, and the effects of inappropriate therapy, insurance, ${ }^{4}$ and attribution of symptoms from non-accident related causes (spontaneous symptoms, occupational symptoms, symptoms before an accident being amplified after an accident).

The design of this earlier study ${ }^{3}$ did not allow for a precise and reliable estimation of the incidence, severity, and duration of initial symptoms. For such an analysis and to identify whether or not the Lithuanian accident victims actually develop an acute injury (which is a prerequisite for chronic disability), we performed a prospective controlled cohort study in Lithuanian citizens recently exposed to a rear end car collision.

\section{Methods}

STUDY GROUP

During 23 months we identified from the daily records of the Traffic Police Department of Kaunas, Lithuania, a consecutive group of 255 cars involved in rear end collisions. The records describe the circumstances of the accident and the vehicular damage. In this period there had been altogether 3616 traffic accidents that had led the traffic police to investigate the accident scene. All cars with description of a rear end damage were included in the present study.

A standard self report questionnaire was sent to the drivers between 2 and 7 days after the accident. They were asked about passengers in their cars, allowing an additional recruitment of accident victims who received the same questionnaire. All were asked about presence, frequency, and intensity of neck pain and headache before the accident. In addition they were asked about circumstances of the accident including confirmation and description of the accident; the subject's position in the car; the 
Table 1 Demographic characteristics of the subjects

\begin{tabular}{lcc}
\hline & Accident victims & Controls \\
\hline Participants (n) & 210 & 210 \\
Sex (n): & & \\
Male & $181(86 \%)$ & $181(86 \%)$ \\
Female & $29(14 \%)$ & $29(14 \%)$ \\
Mean (SD) age (y) & & \\
Men & $39(10)$ & $39(10)$ \\
women & $36(8)$ & $36(8)$ \\
Mean (SD) height (cm): & & \\
Men & $180(5)$ & $178(5)$ \\
Women & $166(3)$ & $166(5)$ \\
Mean (SD) weight (kg): & & \\
Men & $83(11)$ & $79(9)$ \\
Women & $65(8)$ & $65(10)$ \\
Highest education (n): & $2(1 \%)$ & $4(2 \%)$ \\
Primary school & $15(7 \%)$ & $12(6 \%)$ \\
Secondary school & & \\
Practical education/ & & \\
$\quad$ professional school & $103(49 \%)$ & $102(49 \%)$ \\
University graduate & $68(32 \%)$ & $69(33 \%)$ \\
University, uncompleted & $21(10 \%)$ & $23(11 \%)$ \\
$\quad$ Other & $1(0.5 \%)$ & $0(0 \%)$ \\
Marital status (n): & & \\
Single & $24(11 \%)$ & $34(16 \%)$ \\
Married & $166(79 \%)$ & $157(75 \%)$ \\
Widowed & $3(1 \%)$ & $2(1 \%)$ \\
Divorced & $11(5 \%)$ & $14(7 \%)$ \\
Unknown & $6(3 \%)$ & $3(1 \%)$ \\
\hline
\end{tabular}

use of seat belts; position of the head at the time of the accident; and headrest use and adjustment. To evaluate an eventual dose-response relation, the accident victims were asked to estimate the speed of each car at impact, although it was recognised that the estimates may well be inaccurate.

Acute symptoms within 7 days of the accident were evaluated by questions of occurrence, latency, duration, and intensity. The participants were also asked whether they still had symptoms that started after the accident.

Follow up questionnaires ( 2 months and 1 year after the accident) asked detailed questions about current neck pain, neck mobility, and headache. To confirm the initial questionnaire reports, the accident victims were asked in follow up questionnaires again if they had had any neck pain, or headache, or both after the accident, how long these lasted, and whether the complaints were still present.

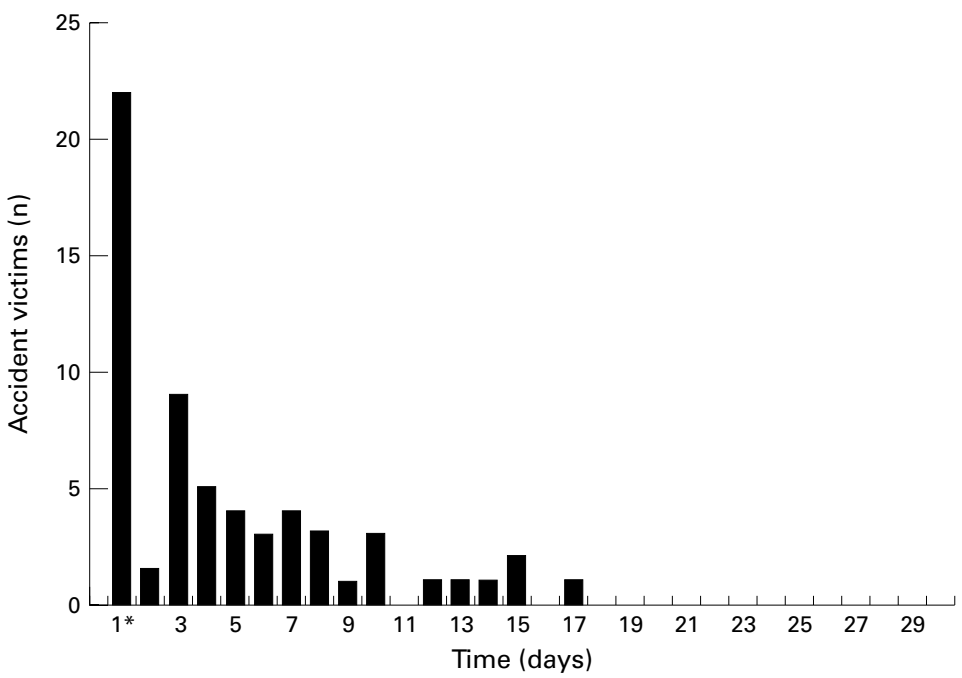

Figure 1 Distribution of duration of neck pain. ${ }^{\star} 24$ hours or less.
CONTROL GROUP

For each accident victim, a sex and age matched control subject was randomly drawn from the population register of the Kaunas region. Excluded from this group were any who had previously been in an accident; then a new selection was made from the registry. The control group received questionnaires at the time of the selection and 1 year later; these questionnaires being identical to the study group questions except that the study group also answered questions about symptoms related to the accident.

\section{STATISTICS}

The four main outcome variables were neck pain and headache $\geqslant 1$ day/month and frequent neck pain or headache ( $>7$ days/month). Proportions were compared between groups using $\chi^{2}$ tests with Yates' correction. Ninety five per cent confidence intervals (95\% CIs) for proportions were calculated.

A power analysis (requesting $80 \%$ power and two sided $5 \% \alpha$ ) was performed to assess the type II error. Assuming a population prevalence of chronic neck pain equal to $7 \%,{ }^{3}$ the present design could detect accident related additional neck pain prevalence of at least $8.7 \%(7 \% v$ $15.7 \%$ ) in two equal groups of 210 subjects. A post hoc power analysis, adjusted for subjects lost for follow up and for the estimated prevalence of acute pain, was also performed.

\section{Results}

Of the 277 accident victims who received the first questionnaire, 210 responded $(76 \%) ; 29$ women (mean age 36 (SD 8) years) and 181 men (mean age 39 (SD 10) years). The questionnaire was on average completed 11 (SD 4) days after the accident. There were 188 drivers (17 women and 171 men), 20 front seat passengers (11 women and nine men) and two rear seat passengers (one woman and one man). The mean estimated collision speed (speed of striking car minus the speed of the rear impacted car estimated by the accident victim) was 40 (SD 19) $\mathrm{km} /$ hour. In $14 \%$ of accidents the rear impacted car was a wreck and could not be driven. In 54\% the damage was moderate and in $32 \%$ minor (dent on bumper or wing). A majority of $67 \%$ had a fastened and operative seat belt. Only 23\% had the upper border of their headrest at or above the occiput; $43 \%$ had no headrest, $11 \%$ had a low mounted headrest, and $23 \%$ had the upper border of their headrest at the cervical lordosis.

The response rate of the control participants was $78 \%$ for the first questionnaire. Nine of the controls had to be excluded because of previous car accidents.

The demographic characteristics of accident victims and controls were similar, confirming adequate randomisation (table 1 ).

In the accident victim group, $94 \%$ answered the questionnaire after 2 months and $95 \%$ after 1 year. In the control group, $92 \%$ responded to the follow up questionnaire at 1 year.

According to the answers to the first questionnaire and the answers to the control questions in the second and third questionnaire, 98 (47\%) 


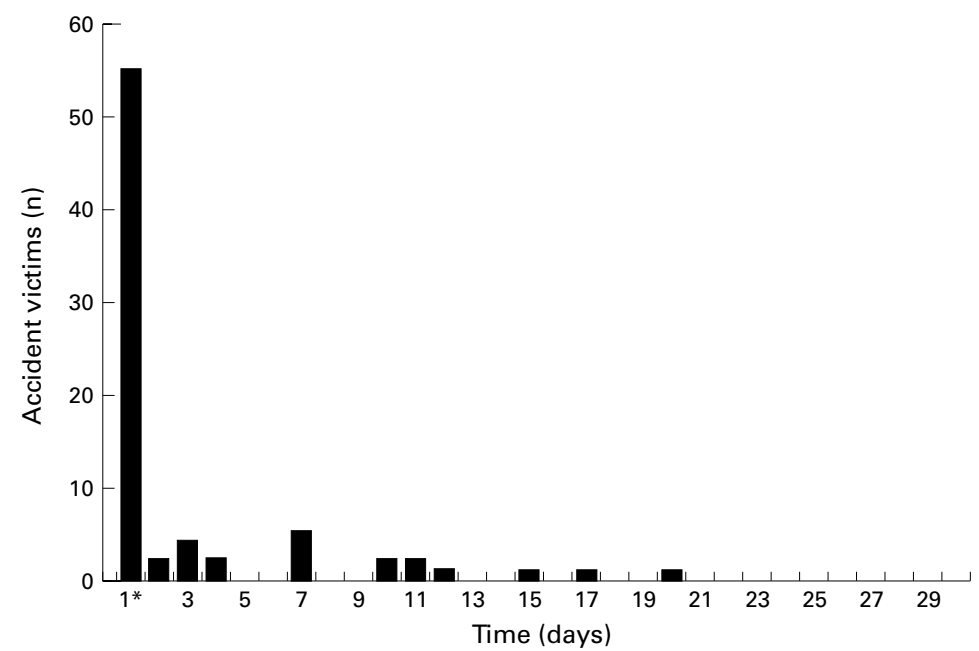

Figure 2 Distribution of duration of headache. ${ }^{*} 24$ hours or less.

subjects experienced pain shortly after the accident; 22 (10\%) had neck pain alone, 37 $(18 \%)$ had neck pain together with headache, and $39(19 \%)$ had headache alone. Onset of neck pain was within 30 minutes in $37 \%$ of the cases, between 30 minutes and 24 hours in $44 \%$, and between 1 and 3 days in $17 \%$. There was only one subject in whom pain occurred between 4 and 7 days after the accident. In this case, neck pain lasted 4 days. The median duration of neck pain was 3 days (range $<3$ hours to 17 days). No subject reported severe or excruciating initial neck pain and only two reported severe initial headache. In no case did the neck pain persist beyond 17 days (fig 1). The median duration of headache was 4.5 hours and no one had accident induced headache beyond 20 days (fig 2 ).

The incidence of acute neck pain was $48 \%$ in those who reported neck pain $\geqslant 1$ day/month before the accident and $25 \%$ in those with no or rare neck pain, before the accident $(\mathrm{p}<0.03)$. The incidence of acute headache was $64 \%$ in those reporting headache $\geqslant 1 \mathrm{day} /$ month be-

Table 2 Incidence of acute neck pain in relation to sex, position in the car, head position at the time of the accident, seat belt use and presence, and adjustment of headrest

\begin{tabular}{|c|c|c|}
\hline Characteristic & Incidence (n (\%)) & p Value \\
\hline \multicolumn{3}{|l|}{ Sex: } \\
\hline Men & $48 / 181(27)$ & $0.30^{\star}$ \\
\hline Women & $11 / 29(38)$ & \\
\hline Position in car: & & $0.16^{\star \star}$ \\
\hline Driver & $49 / 188(26)$ & \\
\hline Front seat passenger & $9 / 20(45)$ & \\
\hline Rear seat passenger & $1 / 2(50)$ & \\
\hline Head position: & & $0.74^{\star \star}$ \\
\hline Straight forward & $41 / 149(28)$ & \\
\hline Turned to the right & $6 / 23(26)$ & \\
\hline Turned to the left & $9 / 26(35)$ & \\
\hline \multicolumn{3}{|l|}{ Seat belt fastened and operative: } \\
\hline Yes & $45 / 134(34)$ & $0.10^{\star}$ \\
\hline No & $14 / 66(21)$ & \\
\hline Headrest: & & $0.22^{\star \star \star}$ \\
\hline No headrest & $21 / 87(24)$ & \\
\hline Low mounted headrest & $5 / 22(23)$ & \\
\hline Border of headrest at lordosis & $17 / 47(36)$ & \\
\hline Border of headrest at/above occiput & $15 / 47(32)$ & \\
\hline $\begin{array}{l}\text { Head not placed on headrest at the moment of the accident } \\
\text { and border of headrest at/above occiput }\end{array}$ & $15 / 40(37)$ & \\
\hline $\begin{array}{l}\text { Head placed on headrest at the moment of accident and } \\
\text { border of headrest at/above occiput }\end{array}$ & $0 / 7(0)$ & \\
\hline
\end{tabular}

fore the accident and $24 \%$ in those with no or rare neck pain before the accident $(p<0.0001)$.

Sex, sitting position in the car, head position at the moment of the accident, use of seat belts, and presence and adjustment of the headrest did not influence the incidence of acute neck pain significantly (table 2). However, among the subjects in whom the headrest was adjusted with the upper border at or above the occiput no one experienced acute neck pain if the head had been placed on the headrest at the time of the collision.

Incidence of initial headache was $58 \%$ in women and $33 \%$ in men $(p=0.01)$. The incidence of initial neck pain in those involved in high speed collision (41-95 km/hour) was 40\% compared with $16 \%$ in those where collision speed was estimated to be below $21 \mathrm{~km} /$ hour $\left(\chi^{2}=6.7, p<0.01\right)$. Thus despite probably highly inaccurate and often overestimated collision speed, a dose-response relation was found. In agreement, in occupants of cars with extensive damage, the incidence of initial pain was $52 \%$ compared with $10 \%$ for those in car accidents with minor damage $\left(\chi^{2}=17.2, \mathrm{p}<0.0001\right)$.

After 1 year, frequent neck pain $(>7$ days/month) was reported by $4.0 \%$ of accident victims (95\% CI 1.9-8.1) compared with $6.2 \%$ of controls (95\% CI 3.4-10.9) $\quad\left(\chi^{2}=0.59\right.$, $\mathrm{p}=0.44$; table 3$)$. Of the eight accident victims with frequent neck pain, the pain was described as mild by five and moderate by three. Three of them had had equally frequent neck pain before the accident. Three others did not report their pain in the second questionnaire after 2 months and did not relate it to the accident. The two others did not report long lasting or marked initial pain. Nor did they attribute their frequent neck pain to the accident. Of the 12 controls with frequent neck pain after 1 year, seven described their pain as mild, four as moderate, and one as severe. Eight of them did not have this neck pain when they completed the first questionnaire.

Neck mobility was after 1 year reported to be constantly reduced by $12 \%$ of accident victims and $18 \%$ of controls $(\mathrm{p}=0.09)$.

Frequent headache ( $>7$ days/month) was reported by $5.1 \%$ of accident victims after 2 months compared with $6.2 \%$ of accident victims who reported having had frequent headache before the accident. After 1 year, frequent headache was reported by $4.0 \%$ of accident victims (95\% CI $1.9-8.1)$ and $6.7 \%$ of controls (95\% CI 3.8-11.5) $\left(\chi^{2}=0.96, \mathrm{p}=0.33\right)$. Headache occurring on $\geqslant 1$ day/month was reported by $27.5 \%$ of accident victims and $33.2 \%$ of controls $\left(\chi^{2}=1.23, \mathrm{p}=0.27\right)$. Two accident victims and four controls had daily headache when interviewed after 1 year. Of the accident victims with frequent headache after 1 year, two described their pain as mild, five as moderate, and one as severe. Of the 13 controls with frequent headache after 1 year, four described their pain as mild, seven as moderate, one as severe, and one as excruciating. Six of them did not have this frequent headache when interviewed immediately after identification.

Our study had $80 \%$ post hoc power to detect a population difference in prevalence of neck 
Table 3 Frequency distribution of neck pain before and after rear end car collision, and in matched controls

\begin{tabular}{llllll}
\hline & $\begin{array}{l}\text { Accident victims } \\
\text { before accident } \\
n=210\end{array}$ & $\begin{array}{l}\text { Controls at } \\
\text { identification } \\
n=210\end{array}$ & $\begin{array}{l}\text { Accident victims } \\
\text { after 2 months } \\
n=198\end{array}$ & $\begin{array}{l}\text { Accident victims } \\
\text { after 1 year } \\
n=200\end{array}$ & $\begin{array}{l}\text { Controls } \\
\text { after 1 year } \\
n=193\end{array}$ \\
\hline $\begin{array}{l}\text { Frequency of neck pain } \\
\text { Neck pain }\end{array}$ & $148(70 \%)$ & $146(70 \%)$ & $132(67 \%)$ & $140(70 \%)$ & $114(59 \%)$ \\
$<$ 1 day per month & $37(18 \%)$ & $38(18 \%)$ & $36(18 \%)$ & $27(14 \%)$ & $39(20 \%)$ \\
1-7 days per month & $18(8.6 \%)$ & $16(7.6 \%)$ & $18(9.1 \%)$ & $25(13 \%)$ & $28(15 \%)$ \\
8-15 days per month & $2(1.0 \%)$ & $4(1.9 \%)$ & $3(1.5 \%)$ & $3(1.5 \%)$ & $4(2.1 \%)$ \\
$>15$ days per month & $1(0.5 \%)$ & $3(1.4 \%)$ & $2(1.0 \%)$ & $0.0 \%)$ & $1(0.5 \%)$ \\
Every day & $4(1.9 \%)$ & $3(1.4 \%)$ & $7(3.5 \%)$ & $5(2.5 \%)$ & $7(3.6 \%)$ \\
\hline
\end{tabular}

pain between groups $\geqslant 9 \%(16 \%$ in 200 accident victims $v 7 \%$ in 193 controls). If only the 98 subjects with acute pain were taken as the group at risk and compared with the remaining 295 subjects, the study still had $80 \%$ power to detect a $11 \%$ population difference. If the groups of our previous and present studies had been combined (797 subjects altogether), population differences of $6 \%$ (accident $v$ non-accident groups) and 7\% (acute pain subjects $v$ pain free persons) respectively could have been detected.

\section{Discussion}

To our knowledge, this is the first prospective controlled inception cohort study of pain after whiplash. It confirms the findings of our earlier historical cohort study that rear end collisions do not seem to increase the risk of chronic pain. The setting was ideal for examining the natural history of acute whiplash injury because potentially intervening factors that could contribute to reporting chronic symptoms are largely absent in Lithuania.

To reduce expectation of symptoms to a minimum, we restricted our study to the use of mailed questionnaires. Any suggestion as to which persistent symptoms the car accident could lead to was avoided in the introductory letter and none of the accident victims was subjected to clinical investigations by us. Because only subjective symptoms were relevant, the last was also deemed unneccesary.

The questionnaire method is not wholly reliable, but any errors would be unbiased in controls and accident victims.

The results showed that just under half of an unselected cohort exposed to a significant whiplash mechanism due to a rear end car collision had acute pain. The symptoms were usually mild or moderate and disappeared in most cases after a few days. No subject reported accident induced pain later than 3 weeks. After 1 year, there were no significant differences between the accident victim group and the control group concerning frequency and intensity of both neck pain and headache.

Several previous studies have reported that symptoms persist after a neck injury in $15 \%-58 \%$ of accident victims. ${ }^{5-9}$ The power of our own two studies (the present study and Schrader $e t a l^{3}$ ), either analysed alone or combined, was sufficient to detect effects of less magnitude $(6 \%-11 \%)$, even if only subjects who reported acute pain were selected for the group at risk.

Prevalence of neck pain and headache were of the same order of magnitude in both the accident victims and controls as found in west- ern countries, ${ }^{10-12}$ confirming that our questionnaires were sensitive enough to find the symptoms in question. The results were also compatible with the notion that pain is experienced similarly by Lithuanians and by people in other cultures.

There is a remarkable agreement between the findings in our study and the findings reported in volunteer experiments with experimental collisions:

Firstly, despite being able to readily produce acute symptoms, thousands of experimental collisions have failed to produce a patient with chronic symptoms, regardless of the use of various vehicles, impact directions, and speeds, with or without headrest, with varying head positions, with or without tensed neck muscles, and more recently with both sexes and a wide range of young and old, and non-military volunteers. ${ }^{13-22}$ In these staged collisions of various types, the reported frequency of symptoms has been as high as $40 \% .{ }^{17}$

Secondly, the duration of neck pain and headache in our study group agrees with that reported in the volunteers of the above quoted collisions. In those, headache has been reported to last for hours or days, with neck pain being reported in some cases lasting as long as 10 days. ${ }^{17}$

Thirdly, as in human volunteer collisions there was a positive relation between incidence of acute neck pain and the severity of collision in our study. Thus, despite probably highly inaccurate and often overestimated collision speed, a dose-response relation was found. This contrasts with claims of limited relevance of impact speed with respect to cervical spine impact. ${ }^{23} 24$

These similarities between the results of experimental collisions and the results in our study group confirm that Lithuanians are not different from subjects in western countries in response to injury.

It has been argued that persistent symptoms are more prevalent among women and passengers. ${ }^{25}$ As could be expected from an unselected cohort of car accident victims, the present sample included a majority of male drivers. This would significantly reduce the power to detect cases with late whiplash syndrome if males and car drivers never or seldom experience acute or sustained pain. To our knowledge, there is no study in which this has been shown. In a recent Norwegian study, 74\% of those registered with neck sprain injuries from car collisions were drivers. ${ }^{9}$ In the same study, $41 \%$ of the injured persons were males and $59 \%$ females. At follow up after 2.5-8.5 years, $53 \%$ of these males and $62 \%$ of the females reported sustained symptoms which 
they attributed to the accident - that is, there were only moderate sex differences. ${ }^{9}$

Presence and even correct position of the headrest did not reduce the incidence of acute pain. Our data suggest that placing the head on a correctly mounted headrest at the moment of the collision may prevent acute neck pain, a result that should serve as an incentive for implementation of headrest constructions that ensure continuous contact with the headrest while driving.

There was no significant difference in incidence of acute neck pain between those who had operating seat belts and those who had not, contrasting with the assumption that the increase of whiplash injuries is mainly due to the introduction of compulsory car seat belts. ${ }^{26}$

Rotated or inclined head position at the time of the impact has been assumed to be the primary feature related to the incidence of persisting symptoms. ${ }^{27}$ As no accident victim in our study continued to have accident related persistent pain we could only evaluate the incidence of acute pain related to head position. No such relation was found, however.

Sixty seven per cent of those in the control group who reported frequent neck pain $(>7$ days/month) in the interview after 1 year and $46 \%$ who reported frequent headache did not report this pain when interviewed for the first time. Hence, spontaneously occurring appreciable neck pain or headache during an observation period of 1 year is frequent also in untraumatised people and may erroneously have been attributed to the accident in studies in western countries.

In Lithuania a minority of car drivers are insured for personal injury, a factor that may have contributed to the divergence between our results and those of many previous studies. It remains difficult to estimate the importance of this contribution as long as numerous other confounding factors that are important in other societies $^{28}{ }^{29}$ are absent in Lithuania.

In summary, in a country where there is no expectation of symptoms or disability, and little involvement of the therapeutic community, acute pain after whiplash is, although frequent, mostly mild or moderate, short lasting, and self limiting. The only identifiable significant risk factors seem to be neck pain or headache before the accident, and female sex for initial headache and impact severity. No case with evolution of chronic accident related pain was identified either in this prospective study of 210 subjects or in our earlier historical cohort study of 202 accident victims.

As almost all previous studies have been done in patients who have contacted the health service because of their injury, and thus may have been partly invalidated by selection bias, it remains to be shown whether the apparent discrepancy between our study and other studies is due to the absence of confounding factors in Lithuania or to the fact that a study with a controlled inception cohort design still has not been performed in western countries.

We thank Danguole Siurkiene and Dalia Mickeviciene for their invaluable work with identification of accident victims and col- lection of data. The study was supported by grants from the Research Council of Norway and the Medical Faculty of the Norwegian University of Science and Technology.

1 Spitzer WO, Skovron ML, Salmi LR, et al. Scientific Monograph of the Quebec Task Force on Whiplash Associated graph of the Quebec Task Force on Whiplash Associated Disorders: redefining "whiplas
Spine 1995;20(suppl 8): 1S-73S.

2 Stovner LJ. The nosological status of the whiplash syndrome: a critical review based on a methodological approach. Spine 1996;21:2735-46.

3 Schrader H, Obelieniene D, Bovim G, et al. Natural evolution of late whiplash syndrome outside the medicolegal context. Lancet 1996;347:1207-11.

4 Schmand B, Lindeboom J, Schagen S, et al. Cognitive complaints in patients after whiplash injury: the impact of malingering. I Neurol Neurosurg Psychiatry 1998;64:33943 .

5 Macnab I. Acceleration injuries to the cervical spine. $f$ Bone Foint Surg 1964;8:1797-9.

6 Norris SH, Watt I. The prognosis of neck injuries resulting from rear-end vehicle collisions. F Bone foint Surg Br 1983; 65:608-11.

7 Deans GT, Magalliard JN, Kerr M, et al. Neck sprain-a major cause of disability following car accidents. Injury 1987;18:10-12

8 Pearce JMS. Whiplash injury: a reappraisal. 7 Neurol Neurosurg Psychiatry 1989;52:1329-31.

9 Borchgrevink GE, Lereim I, Røyneland L, et al. National health insurance consumption and chronic symptoms following mild neck sprain injuries in car collisions. Scand $\mathcal{F}$ Soc Med 1996;4:264-71.

10 Hasvold T, Johnsen R. Headache and neck or shoulder pain-frequent and disabling complaints in the general population. Scand f Prim Health Care 1993;11:219-24.

11 Bovim G, Schrader H, Sand T. Neck pain in the general population. Spine 1994;19:1307-9.

12 Göbel H, Petersen-Braun M, Soyka D. The epidemiology of headache in Germany: a nationwide survey of a representative sample on the basis of the headache classification of the tive sample on the basis of the headache classification of the
International Headache Society. Cephalalgia 1994;14:97106.

13 Severy DM, Mathewson JH, Bechtol CO. Controlled automobile rear-end collisions, an investigation of related engineering and medical phenomena. Can Serv Med $\mathcal{F}$ 1955;11: $727-59$

14 Mertz HJ Jr, Patrick LM. Investigation of the kinematics and kinetics of whiplash. Proceedings of the 11th Stapp Car Crash Conference; Society of Automotive Engineers, 1967:175-206. (SAE paper No 670919.)

15 Ewing CL, Thomas DJ, Lustick L, et al. The effect of the initial position of the head and neck on the dynamic response of the human head and neck to Gx impact acceleration. Proceedings of the 19th Stapp Car Crash Conference; eration. Proceedings of the 19th Stapp Car Crash Conference;
Society of Automotive Engineers, 1975:487-512. (SAE paper Society of Automo
No 751157 .)

16 Ewing CL, Thomas DJ, Lustick L. Multiaxis dynamic response of the human head and neck to impact acceleration. Proccedings of the AGARD conference $253 ; 1978$ November; France. 1979;A5:1-27.

17 Thomas DJ, Ewing CL, Majewski PL, et al. Clinical medical effects of head and neck responses during biodynamic stress experiments. Proceedings of the AGARD conference 267; 1979; Lisbon, Portugal. 1979;15:1-15.

18 Sances A Jr, Weber RC, Larson SJ, et al. Bioengineering analysis of head and spine injuries. Critical Reviews in Biomedical Engineering 1981;5:79-118.

19 McConnell WE, Howard RP, Guzman HM, et al. Analysis of human test subject kinematic responses to low speed rear end impacts. Proceedings of 37th Stapp Car Crash Conference; Society of Automotive Engineers, 1993:21-30. (SAE paper No 930889.)

20 West DH, Gough JP, Harper GTK. Low speed rear-end collision testing using human subjects. Accident Reconstruction fournal 1993;5:22-6.

21 Baily M. Assessment of impact severity in minor motor vehicle collisions. F Musculoskeletal Pain 1996;4:21-38.

22 Gough JP. Human occupant dynamics on low-speed rear end collisions: an engineering perspective. Vancouver, Canada: collisions: an engineering perspective. Van

23 Sturzenegger M, Di Stefano G, Radanov BP, et al. Presenting symptoms and signs after whiplash injury: the influence of accident mechanisms. Neurology 1994;44:688-93.

24 Radanov BP, Sturzenegger M, Di Stefano G. Long-term outcome after whiplash injury: a 2 year follow up considering features of accident mechanism and somatic, radiologic and psychosocial findings. Medicine 1995;74:281-97.

25 Bjørgen I. Late whiplash syndrome [letter]. Lancet 1996; 348:124.

26 Thomas J. Road traffic accidents before and after seat belt legislation: a study in a district general hospital. $\mathcal{F} R$ Soc Med 1990;83:79-82.

27 Sturzenegger M, Radanov BP, Di Stefano H. The effect of accident mechanism and initial findings on the long term course of whiplash injury. 7 Neurol 1995;242:443-9.

28 Ferrari R, Russell AS. The whiplash syndrome: common sense revisisted. F Rheumatol 1997;24:618-23.

29 Drottning M, Staff PH, Levin L, et al. Acute emotional response to common whiplash predicts subsequent pain complaints. Nordic Fournal of Psychiatry 1995;49:293-9. 